\title{
Simple Release of an Impacted Dormia Basket during Endoscopic Bile Duct Stone Extraction
}

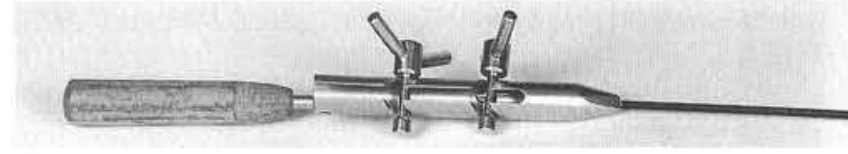

Figure 1: The AO (ASIF) wire tightener with a standard coated bicycle brake-cable.

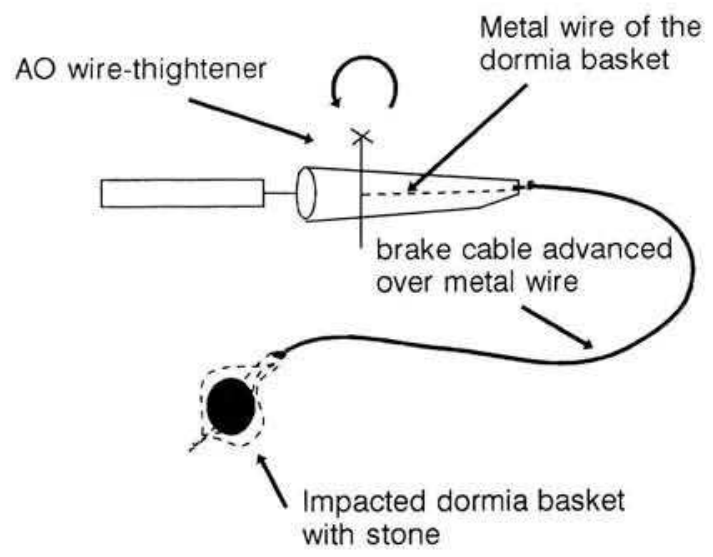

Figure 2: Schematic drawing of the procedure.

Endoscopic treatment of bile duct stones is more difficult and hazardous with stones whose diameter exceeds 15 to $20 \mathrm{~mm}(1,2)$. Stone impaction during basket extraction is a rare, but well known complication (1-4). We describe a simple technique to release stones impacted during attempted basket extraction. The instruments used for this purpose are available in every surgical or orthopaedic department. When bile stones become impacted together with the Dormia basket the endoscope is removed. Under $\mathrm{x}$-ray control a standard plastic coated bicycle brake-cable, with a length of about one meter, is advanced over the metal wire up to the open basket. Thereafter the wire is connected to an AO (ASIF)- wire tightener, which is normally used for tension band wiring of fractures (Fig-ure 2). Tightening of the catheter wire puts the basket under high tension so that either the stone is fragmented or the basket ruptures to release the equipment and/or clear the bile duct (Figure 1).The described technique was applied in our hospital in five patients since 1986. In all cases stones were crushed successfully. Complications were not seen and wire breakage did not occur. This may also be due to the fact that large bile stones tend to have a more or less soft consistency. This method is successful, simple and safe while the equipment is cheap and immediately available.

H. van Dullemen*(I), W. N. H. M. Stuifbergen ${ }^{(I)}$,

J. R. Juttmann ${ }^{(l)}$, C. van der Werken ${ }^{(2)}$

(1) Department of Internal Medicine,

(2) Department of General Surgery,

St. Elisabeth Hospital, P.O. Box 90151 ,

5000 LC Tilburg, The Netherlands

\section{References}

1. Cotton PB: Non-operative removal of bile duct stones by duodenoscopic sphincterotomy. Br. J. Surg. 1980; 67: 1-5.

2. Leese T, Neoptolomus JP, Carr-Locke DL: Successes, failures, early complications and their management following endoscopic sphincterotomy: results in 394 consecutive patients from a single centre. $\mathrm{Br}$. J. Surg. 1985; 72: 215-219.

3. Neuhaus B, Safrany $L$ : Complications of endoscopic sphincterotomy and their treatment. Endoscopy 1981; 13: 197-199.

4. Weitemeyer RA: Endoscopic sphincterotomy: A procedure of choice in the management of retained common bile duct stones and papillary stenosis. Am. J. Surg. 1982; 142: 537-539. 